UDC $66.084 .8+667.274 .2$

\title{
RESONANT ACOUSTIC EFFECT ON EXTRACTION OF BIRCH INNER BARK WITH ALKALI SOLUTION
}

\author{
(C) E.O. Bobkova, N.G. Kostyukevich, D.N. Vedernikov" \\ St. Petersburg State Forest Technical University named after S.M.Kirov, Institutsky \\ per., 5, St-Petersburg, 194021 (Russia)
}

The article describes the option of intensification extraction process from the birch inner bark. The influence of acoustic action (tensile-pulse modulation) on an increase in the yield of extractive substances on an aqueous solution of alkali $(1 \% \mathrm{NaOH})$ is discussed. The extraction results were evaluated by the solid residue, the optical density of the solution, and the content of tannins. The yield of extractive substances is increased in 1.5 time with the help of a certain generator signal (meander) with a certain frequency (in the range of 170-190 kHz) and amplitude (2.7-2.9 V). The acoustic effect makes it possible to increase the yield of extractive substances by $17 \%$ if compared with the yield with mechanical stirring. The purity of tannin can be improved by adding ethyl alcohol to the extractant. The effect of background regulation with signal power less than $1.5 \mathrm{~mW}$, exceeds the effect of mechanical mixing. A meander has the greatest effect in a series of electromagnetic signals: a meander, a sine, a triangle, a rectangle. The extraction time is determined. All counterparts taken into consideration the effect occurs. The cause of this phenomenon is examined. An explanation of the results is given.

Key words: birch inner bark, extractive substances, tannins, sodium hydroxide solution, acoustic effect.

\section{Introduction}

Birch wood is widely used in the pulp and paper industry, at plywood factories. In wood preparing for processing, bark remains. The relative content of bark in the used part of the birch trunk (Betula pendula Roth.) is 12$15 \%$. The bark contains $8.6 \%$ of inner bark and $5.4 \%$ of outer bark [1]. The content of the bark and its elements depends on the age, species and height of a tree.

After bark grinding inner bark of birch can be separated from outer bark by means of small bast particles sieving, heavier bast particles soaking and light outer bark blowing $[2,3]$.

Inner bark of birch is a potential source of tannins - condensed tannins, the content of which reaches $8-11 \%$ [4]. Condensed tannins have the anthelmintic activity [5, 6], the anti-nutritional effect, actively interact with metals to form complexes [7], which are used to combat helminths [5]. Condensed tannins actively bind protein. This ability is used for tanning skin [7]. These substances can be used as a phenol substitute in the synthesis of phenol-formaldehyde resins, they are a good crosslinking agent in the synthesis of polyurethanes, adsorb heavy metal ions. They also have antimicrobial, antitermite and growth-regulation activities [7].

It has been proposed to use birch inner bark to obtain tannins, using extraction with a water-alcohol alkaline solution [8]. At the same time the problem of solvent regeneration has not been inverstigated. To isolate extractive

Bobkova Elena Olegovna - Department of Technology of

Wood Chemical Products, Wood Chemistry and

Biotechnology, master student, e-mail: gluk-lena@rambler.ru

Kostukevich Nataliya Garrievna - Department of Technology

of Wood Chemical Products, Wood Chemistry and

Biotechnology, Associate Professor, Ph.D. of Chemistry,

e-mail:kvado@mail.ru

Vedernikov Dmitriy Nikolaevich - Department of Technology

of Wood Chemical Products, Wood Chemistry and

Biotechnology, Professor, D.Sc., Associate Professor,

e-mail: dimitriy-4@yandex.ru substances and the tannins from the inner bark of the birch, we propose extraction with an aqueous solution of $1 \% \mathrm{NaOH}$. An increase in the yield of tannins can be achieved if the tensile-pulse modulation is applied to the extractor.

Acoustic influence or tensile-pulse modulation can increase the rate of chemical reactions, as well as increase heat transfer and mass transfer [9]. The tensile-pulse modulation is a change in the parameters of

\footnotetext{
* Corresponding author.
} 
impulse signals in time or in space. Usually this process is a kind of modulated oscillations, where a sequence of pulses is used as a "bearer" of information.

There is an optimal frequency of influence on the speed of the process and the properties of the materials obtained [10]. For the chemical processes, the theoretical basis of the tensile-pulse modulation is proposed, based on modern physical and physicochemical concepts, fundamental laws, mathematical analysis, and the computer simulation apparatus. The regime is justified by the background regulation of physicochemical processes by ultra-weak signals corresponding to the fine mechanisms of self-organization of mechanical structures. The existence of upper amplitude thresholds regulate strain-pulse balance, which distinguishes it from the directive methods of natural selforganization course gross violation [10,11].

The aim of our work was to demonstrate a weak acoustic effect can intensify the extraction of the birch inner bark with an alkali solution.

\section{Experiment}

Material. Birch trees (5 samples) (Betula pendula Roth.) were harvested in the village of Pesochny, Leningrad region, in 2003. The inner bark collected at an altitude of 0.1 of the total tree height $(25 \mathrm{~m})$ or at a height of $2.5 \mathrm{~m}$ from the ground, respectively, was used for the experiments. Sampling was done after harvesting of trunk tree. The age of the tree, which was used to study the influence of various factors was about 55 years. The inner bark was separated from the wood and outer bark by hand and ground. The prepared raw materials were dried to air-dry condition. For the experiments, a $0.5-0.25 \mathrm{~mm}$ fraction was selected. Inner bark stored in a refrigerator at $-18^{\circ} \mathrm{C}$

The bark of the other 4 trees of the same species, ages from 35 to 50 years, was selected to compare the extraction results. The inner bark was extracted with light petroleum $\left(40-70{ }^{\circ} \mathrm{C}\right)$ so that the lipophilic substances did not interfere with extraction with an aqueous solution. The yield of the extract was $1.3 \%$. The chemical composition of the raw materials was as follows: substances extracted with diethyl ether -3.0 , ethanol $-15.8 \%$ (the figures mentioned in the text are presented as percentage relative to the initial absolutely dry material), hot water -19.3 , alkali solution -25.5 , mineral substances -1.5 , nitrogen -0.5 , substances after extraction with solvents and $1 \%$ solution of $\mathrm{NaOH}$ : lignin (Klason) - 18.1, holocellulose - 38.7, cellulose - 23.4, pentosans - 21.8 [1].

Extraction conditions. Extraction of raw materials was carried out in a glass flask with a volume of 100 and 500 $\mathrm{ml}$ (1) with stirring and heating on a magnetic stirrer (3) with the connection of an electromagnetic generator (4) to the aerial in the form of a steel clamp (2) at the neck of the flask (Fig. 1). The power of the impact signal in obtaining better results did not exceed $1.5 \mathrm{mV}$. For the experiment signal generator UTG9002C was used with the following specifications: upper limit: $2 \mathrm{MHz}$; waveform: sinusoidal, rectangular, triangular, pulsed, sawtooth; frequency: $0.2 \mathrm{~Hz}-2 \mathrm{MHz}$.

Accuracy $\pm 1 \%$. Resolution $1 \mathrm{mHz}$. Amplitude: range (no load) from $1 \mathrm{mVpp}$ to $20 \mathrm{Vpp}$. Accuracy $\pm 5 \%$. Resolution $0.1 \mathrm{mV}$. Accuracy $\pm 5 \%$. Resolution $0.1 \mathrm{mV}$. Output Power $2 \mathrm{Wpp}$. Output Impendance $50 \Omega$. Attenuator $20 \mathrm{~dB}+40 \mathrm{~dB}$.

Vibration resulting in a tensile-pulse action in the flask occurred due to the reduction - lengthening the size of the conductor - aerial during a short circuit from the two connected generator contacts.

A sample of air-dried inner bark particles $(1 \mathrm{~g})$ was placed in a $100 \mathrm{ml}$ conical flask and $10 \mathrm{ml}$ of a $1 \%$ aqueous solution of $\mathrm{NaOH}$ was added. Bulk weight with content was $76 \mathrm{~g}$ The scaling process was tested in a $500 \mathrm{ml}$ flask with added $400 \mathrm{ml}$ of alkali solution and $40 \mathrm{~g}$ of inner bark. Bulk weight with content was $602 \mathrm{~g}$. A solution of $1.5 \%$ $\mathrm{NaOH}$ was used for the extraction of the inner bark in an alcohol-water medium (15\% ethanol), as shown by the best results, published in [8]. A sample of air-dried inner bark particles $(1 \mathrm{~g})$ was placed in a $100 \mathrm{ml}$ conical flask and $10 \mathrm{ml}$ of a $1.5 \%$ alcohol-water solution of $\mathrm{NaOH}$ was added.

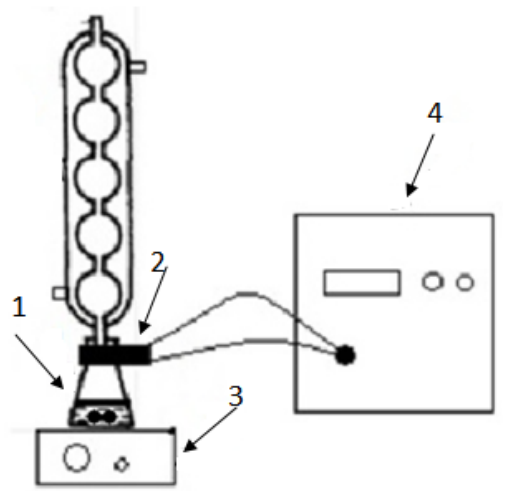

Fig.1 Installation scheme for extraction with acoustic effect 
Stirring and heating to the temperature of $85^{\circ} \mathrm{C}$ was carried out with a magnetic stirrer $(110 \mathrm{rpm})$ and the flask was connected to a reflux condenser. The generator generated electromagnetic oscillations with a frequency of 3 to $500 \mathrm{kHz}$ and an amplitude of 0.4 to $5 \mathrm{~V}$. The frequency deviation was $1 \mathrm{kHz}$, the amplitude deviation was $0.1 \mathrm{~V}$. The extraction temperature does not exceed $75^{\circ} \mathrm{C}$ when using a water-alcohol solution.

Analysis of extraction results. After the extraction had been finished the content was filtered through a glass filter (medium porosity) under vacuum and washed with $150 \mathrm{ml}$ of hot water. The filter funnel with the residue was dried to constant weight at $\mathrm{t}=100-105^{\circ} \mathrm{C}$. The filtrate (extract) was diluted with water to $250 \mathrm{ml}$. The resulting solution was used to determine the content of residue by the solution drying, the determination of "phenolic compounds" was carried out by the permanganate titrimetric method [12]. The tannins were determined in solution by the permanganate method after tannin precipitated with gelatin to assess the purity of the tannins extracts [12]. Calculations of residue from drying the solution and the residue on the filter funnel were carried out regarding absolutely dry bark (a.d.b). The resulting solution was 20 times diluted. For this, $10 \mathrm{ml}$ of the solution was transferred to a $200 \mathrm{ml}$ volumetric flask and the volume of the solution was increased to the mark. In the resulting solution, the optical density of phenolic compounds was determined at a wavelength of $276 \mathrm{~nm}$ on the UV spectrum (Shimadzu UV-2401PC). This wavelength corresponded to the maximum in the spectrum.

\section{Results and discussion}

Effect of temperature. The yield of extractive substances (the dry solids in solution) increased from $15 \%$ to $24.5 \%$ with an increase in temperature from 65 to $85^{\circ} \mathrm{C}$.

Influence of signal frequency. An increase in the yield of extractive substances was observed with any shape of the meander in the interval of the studied frequencies $(3-500 \mathrm{kHz})$. In addition, there was a pronounced maximum of the tuned frequency. At this maximum, the optical density of the solution, the content of the residue from drying the solution, the content of phenolic compounds (Fig. 2) increased to a greater extent and the amount of solid residue decreased (Fig. 3).All analyzes of the extraction results were correlated with each other. The relative standard deviation (RSD) of the experiments was 0.45 .

Amplitude effect. The yield of extractive substances also depended on the amplitude of the signal. The greatest yield was observed at an amplitude of $2.8 \mathrm{~V}$ (Fig. 4). At a different maximum (1.25 V), a change in frequency (200 and $170 \mathrm{kHz}$ ) led to a decrease in the yield of extractive substances. Perhaps the oscillation frequency was crucial. The RSD of the experiments was 0.5 .

Fig.2. Dependence of the "phenolic compounds" content in the extract on the processing frequency (time $180 \mathrm{~min}$, amplitude $2.5 \mathrm{~V}$, meander, $\mathrm{t}=85^{\circ} \mathrm{C}$ ). $\mathrm{X}$ - frequency, $\mathrm{kHz}$; $\mathrm{Y}$ - phenolic compounds, \% a.d.b.

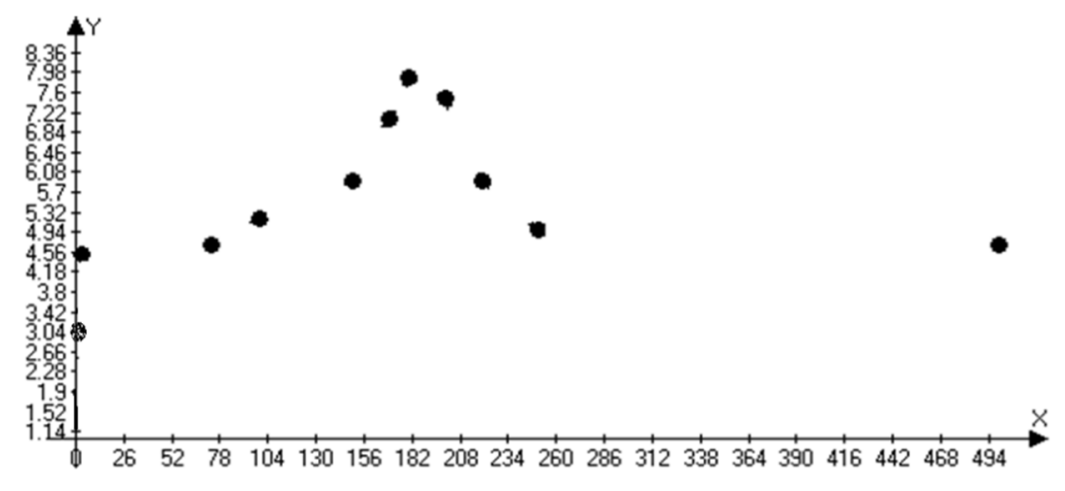

Fig. 3. Dependence of the yield of the solid residue on the processing frequency (time $180 \mathrm{~min}$, amplitude $2.5 \mathrm{~V}$, meander, $\mathrm{t}=85^{\circ} \mathrm{C}$ ). $\mathrm{X}$-frequency, $\mathrm{kHz}$; $\mathrm{Y}$ - residue from drying the solution, $\%$ a.d.b.

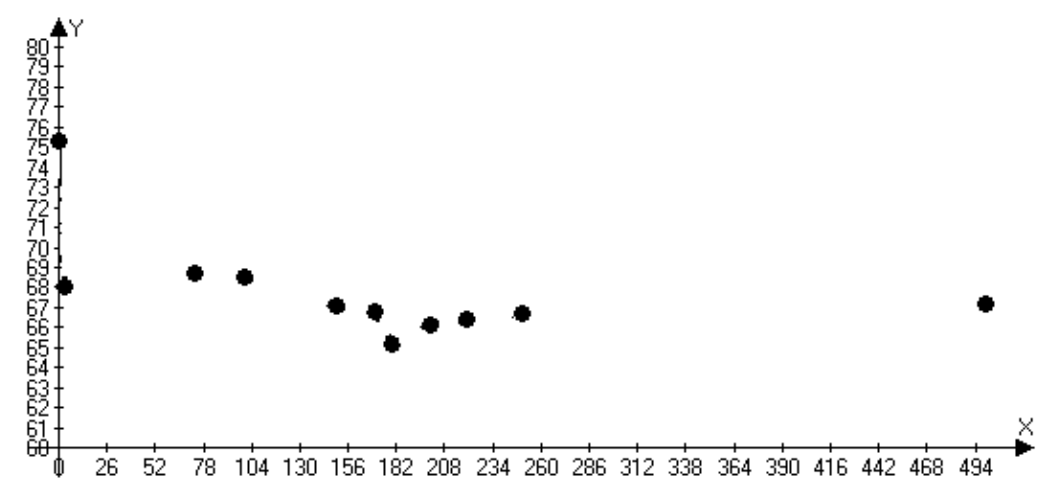




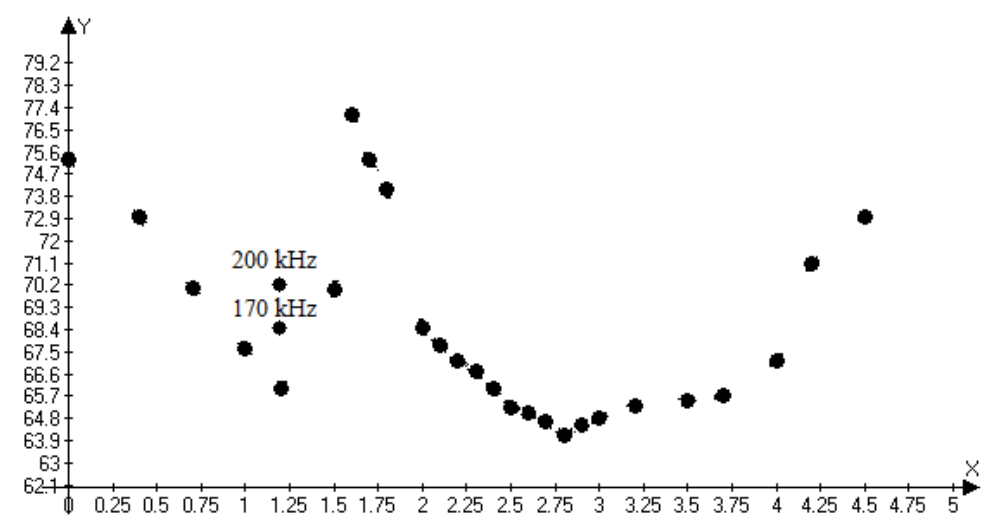

Fig.4. Dependence of the amount of solid residue on processing intensity (time $180 \mathrm{~min}$, frequency $180 \mathrm{kHz}$, meander, $\mathrm{t}=85^{\circ} \mathrm{C}$ ). $\mathrm{X}$ is the amplitude, $\mathrm{V}$; $\mathrm{Y}$ is a residue from drying the solution, $\%$ a.d.b.

Summary: the effect on the flask and its content with a frequency of $180 \mathrm{kHz}$ leaded to an increase in the yield of the phenolic compounds by a factor of 6 . The optical density of solutions obtained after extraction of inner bark of birch tree in other specimens better conditions correlated. The results of the analysis of residue from drying the solution, the amount of solid residue, optical density and the content of tannins correlated with each other, when the factors were changed in all cases.

The influence of time. The increase in extraction time from 180 to $240 \mathrm{~min}$ did not lead to an increase in the yield of extractive substances (Table 1).

Waveform effect. The generator allowed to change the shape of the signal of electromagnetic oscillations and to observe how the process is affected by different signals. Impulse signals showed better results (Table 2). The advantage of the wave form in the form of a meander compared to smoother signals was discussed in [13, 14]. A meander with a duty cycle of 2 gives greater pressure by the electromagnetic acoustic transducer. The advantage of this signal is confirmed.

Effect of stirring and scaling. Since the acoustic power was less than $1.5 \mathrm{~mW}$, it was interesting to compare the mixing effect with the magnetic stirrer and the effect of the sound effect. The power of the magnetic mixer was 9 W. It turned out that the acoustic effect on extraction exceeded mixing (Table 3). Effect also remained with the increase in the size of the flask and the amount of solution and inner bark.

The effect of the addition of ethanol. The purity of tannin extract is increased by the use of water-alcohol solution of alkali in conditions similar to those used in [8]. The effect of the tensile-pulse modulation in this case is preserved (Table. 4).

Table 1. Effect of the extraction time of the inner bark with a solution of alkali with a tensile-pulse influence $(180 \mathrm{kHz}, 2.8 \mathrm{~V}$, meander)

\begin{tabular}{c|c|c}
\hline Time, $\min$ & Solid residue after extraction, \% a.d.b. & Optical density at wavelength, $276 \mathrm{~nm}$ \\
\hline 240 & 64.5 & 0.675 \\
180 & 64.6 & 0.670 \\
150 & 65.1 & 0.620 \\
120 & 65.8 & 0.617 \\
90 & 67.1 & 0.592 \\
\hline
\end{tabular}

Table 2. Influence of the form of generated oscillations on extraction. Conditions: time 180 min, temperature $85^{\circ} \mathrm{C}$, frequency $180 \mathrm{kHz}$, amplitude $-2.8 \mathrm{~V}$

\begin{tabular}{c|c|c}
\hline Waveform & Solid residue after extraction, \%, a.d.b. & Optical density at wavelength, 276 nm \\
\hline Meander & 64.1 & 0.670 \\
\hline
\end{tabular}

\footnotetext{
* The duty cycle is 8
} 
Table 3. The combined effect of mechanical stirring and tensile-pulse modulation on extraction (time 180 min; $\left.180 \mathrm{kHz} ; 2.8 \mathrm{~V} ; \mathrm{t}=85^{\circ} \mathrm{C}\right)$

\begin{tabular}{c|c|c|c}
\hline Acoustic effect & Stirring & Solid residue after extraction, \% a.d.b. & Optical density at wavelength $276 \mathrm{~nm}$ \\
\hline- & - & 75.3 & 0.571 \\
- & + & 70.6 & 0.596 \\
+ & - & 67.4 & 0.626 \\
+ & + & 64.1 & 0.670 \\
+ & + & $65.1^{*}$ & $0.669^{*}$ \\
\hline
\end{tabular}

* The amount of solution and inner bark was 5 times increased

Table 4. The effect of the addition of ethanol and tensile-pulse modulation on extraction (time $180 \mathrm{~min}$ ).

\begin{tabular}{l|c|c|c|c}
\hline $\begin{array}{c}\text { Frequency, kHz; amplitude, V; tempera- } \\
\text { ture, }{ }^{\circ} \mathrm{C} ; \text { extractant }\end{array}$ & $\begin{array}{c}\text { Solid residue after } \\
\text { extraction, } \% \text { a.d.b. }\end{array}$ & $\begin{array}{c}\text { "Phenolic } \\
\text { compounds"* }\end{array}$ & Tannins ${ }^{* *}$ & $\begin{array}{c}\text { The purity of tan- } \\
\text { nin extract, } \%{ }^{* * *}\end{array}$ \\
\hline$-;-; 75 ; 1.5 \% \mathrm{NaOH}$ in $15 \%$ ethanol & 74.9 & 3.1 & 3.0 & 14 \\
$180 ; 2.8 ; 75 ; 1.5 \% \mathrm{NaOH}$ in $15 \%$ ethanol & 65.6 & 11.1 & 9.0 & 27 \\
$-;-; 85 ; 1 \% \mathrm{NaOH}$ in water & 75.3 & 3.0 & 2.8 & 12 \\
$180 ; 2.8 ; 85 ; 1 \% \mathrm{NaOH}$ in water & 64.1 & 7.9 & 6.0 & 17 \\
\hline
\end{tabular}

${ }^{\bar{*}}$ The determination of "phenolic compounds" was carried out by the permanganate titrimetric method [12]; ${ }^{* *}$ The determination of "tannins" was carried out by the permanganate method after tannin precipitated with gelatin. Tannins include substances precipitated with gelatin [12]; ${ }^{* * *}$ The ratio of the content of tannins to the dry residue of the extract.

The yield of extractive substances is increased by using of tensile-pulse modulation both in a water-alkaline medium from 23.9 to 35.1 percent, and in an aqueous-alcoholic medium from 21.4 to 33.4 percent.

\section{Conclusions}

The yield of extractive substances is increased in 1.5 time with the help of a certain generator signal (meander) with a certain frequency (in the range of 170-190 kHz) and amplitude $(2.7-2.9 \mathrm{~V})$. The acoustic effect makes it possible to increase the yield of extractive substances by $17 \%$ in comparison with the yield with mechanical stirring. The purity of tannin extract is low, but it can be improved by adding ethyl alcohol to the extractant and applying ultrafiltration, as suggested in [8].

Pulse signal on the generator in the form of a meander shows the best effect increasing the size of the extractor and the amount of raw material by 5 times not leading to a decrease in the acoustic effect. The frequency is ultrasonic, but the power of the exposure does not exceed $1.5 \mathrm{mV}$ in contrast to the known methods of using ultrasound for extracting of vegetable raw materials, where the power of the action is from $20 \mathrm{~W}$ to a $1 \mathrm{~kW}$ [15-18]. In these cases, the factors contributing to the intensification are: an increase in the speed of flow; acceleration of solid particles impregnation of a solid; an increase in the coefficient of internal diffusion; cavitation effect, affecting the structure of porous bodies and leading to the appearance of microcracks. Tissues of plant material are actively destroyed, which leads to an intensification of the extraction process and allows increasing the content of biologically active compounds in solution.

Unlike traditional ultrasound method the method used leads to the process changes as a result of weak directive influences. The applied external impact is not energy intensive. Apparently, the self-organization of turbulent motion at the phase boundary increases. Synchronous low-frequency resonance vibrational-rotational motions of fluid layers are formed here. The weak vibration transmitted by the antenna is perceived by the fluid layers as a regular signal, and the process acquires space-time ordering. If the spectrum, phase and amplitude characteristics of the external signal are adapted to the system, it responds so that the amplitude increases.

The layers of the solution undergo cyclic pumping. Such waves are self-sustained, synchronized against the background of a constantly acting acoustic signal. The waves propagate along the transition boundary from an aqueous solution of alkali to the cell wall of the inner bark, which allows the extractant to penetrate deeper into the cell wall and extract more extractive substances.

\section{References}

1. Vedernikov D.N., Shabanova N.Y., Roshchin V.I. Russian Journal of Bioorganic Chemistry, 2011, vol. 37, no. 7, pp. 877-882. DOI: 10.1134/S1068162011070259.

2. Voskresensky V.E. Bulletin of St. Petersburg LTA, 1996, vol. 162, no. 4, pp. 106-115. (in Russ.). 
3. Patent 7264184 (US). 2007.

4. Laitinen M.-L., Julkunen-Titto R., Yamaji K., Heinonen J., Rousi M. OIKOS, 2004, vol. 104, pp. 316-326. DOI: 10.1111/j.0030-1299.2004.12793.x

5. Martins M.S. Use of Condensed Tannins Supplementation and Inorganic Copper as Deworming Agents in Naturally Infected Ewes and Lambs. LSU Master's Theses. 2011. 1571 p.

6. Naumann H.D., Tedeschi L.O., Zeller W.E., Huntley N.F. R. Bras. Zootec., 2017, vol. 46, no. 12, pp. 929-949. DOI: 10.1590/S1806-92902017001200009

7. Ohara S. JARQ, 1994, vol. 28, pp. 70-78.

8. Ryazanova T.V., Kuznetsov B.N., Kuznetsova S.A., Levdansky V.A., Chuprova N.A., Kiselev E.G. Khimiya Rastitel'nogo Syr'ya, 2004, no. 3, pp. 29-33.

9. Laine J.E., MacLeod J.M., Bolker H.I., Goring D.A. Pap. Puu., 1977, vol. 59, no. 4a, pp. 235-247.

10. Zarembo V.I., Kolesnikov A.A. Theoretical Foundations of Chemical Engineering, 2006, vol. 40, no. 5, pp. $483-495$. DOI: $10.1134 / \mathrm{s} 0040579506050058$ ()

11. Kolesnikov A.A., Zarembo V.I. Alternativnaya energya i ekologya, 2011, vol. 98, no. 6, pp. 99-108. (in Russ.).

12. Khasnabis J., Rai C., Roy A. J. Chem. Pharm. Res., 2015, vol. 7, no. 6, pp. 238-241.

13. Kolesnikov A.A. Background acoustic regulation of physical and chemical processes in the condensed systems: Abstract of the thesis of the Doctor of Chemistry. St. Petersburg. 2007. 38 p. (in Russ.).

14. Kolesnikov A.A. Background acoustic regulation of physical and chemical processes in the condensed systems: Diss.of the Doctor of Chemistry. St. Petersburg. 2007. 450 p. (in Russ.).

15. Patent 2104733 (RU). 1998. (in Russ.).

16. Sivakumar V., Verma V.R., Rao P.G., Swaminathan G. J. of Cleaner Production, 2007, issue 18, pp. 1813-1818.

17. Mäntysalo M., Mäntysalo E. Ult., 2000, vol. 38, no. 1-8, pp. 723-726.

18. Arroy J.D.V., Ruiz-Espinosa H., Luna-Guevara J.J., Luna-Guevara M.L., Hernández-Carranza P., Ávila-Sosa R., OchoaVelasco C.E. Czech J. Food Sci., 2017, vol. 35, no. 5, pp. 456-465. DOI: 10.17221/316/2016-CJFS

Received September 13, 2018

Revised February 7, 2019

Accepted February 8, 2019

For citing: Bobkova E.O., Kostyukevich N.G., Vedernikov D.N. Khimiya Rastitel'nogo Syr'ya, 2019, no. 3, pp. $285-290$. (in Russ.). DOI: 10.14258/jcprm.2019034391. 